\title{
THE PULMONARY COMPONENT OF THE SECOND HEART SOUND IN FALLOT'S TETRALOGY
}

\author{
BY \\ O. B. TOFLER \\ From the Cardiac Unit, Princess Margaret Hospital for Children, Perth, Western Australia
}

Received April 16, 1962

In some infants and children with classical tetralogy of Fallot the pulmonary component of the second heart sound (P2) can be well heard with the ordinary stethoscope, although there are statements to the contrary in older textbooks.

Because of the difficulty of accurate auscultation due to the normal tachycardia of children it was decided to undertake careful phonocardiographic studies in such cases with a view to determining the frequency with which P2 could be demonstrated.

\section{SubJeCtS AND Methods}

The 18 children who form the basis of this study have all had symptoms severe enough to warrant surgery, mostly in the form of an anastomotic operation (Table I).

All children have been obviously cyanosed at rest, have had clubbing of the fingers, and all, except one, squatted periodically. Clinically they have had a quiet heart with a systolic murmur and thrill maximal in the third left intercostal space near the sternum. There were no murmurs in diastole. The electrocardiogram has shown right ventricular hypertrophy, and the radiogram showed diminished pulmonary blood flow. Three had a right-sided aorta.

Four patients, Cases 1, 2, 3, and 5, did not receive special investigations. Typical catheterization findings were obtained in the seven patients that were so investigated.

Failure to demonstrate early aortic filling in 2 out of 6 patients investigated by angiocardiography is attributed to a faulty technique, i.e. slow injection. Failure to obtain a right-to-left pattern in 2 of 6 patients investigated by dye studies at the time of either catheterization or angiography was attributed either to a streaming effect or a hæmodynamic change produced by anæsthesia.

Three patients with Fallot's tetralogy without obvious cyanosis at rest or clubbing were not included in this group of 18-they all had an audible or easily recordable P2. One patient with virtual pulmonary atresia as well as two patients with the pentalogy of Fallot have been excluded.

Recognition of $\mathbf{P 2}$ is best made in a high frequency tracing. These tracings were obtained with the N.E.P. photographic recorder which has microphones of the Pieza crystal type, fixed by suction to the chest wall.

Often young children are uncooperative and the sedation that is employed can lead to stertorous breathing that mars the phonocardiogram. Much time and patience were required to obtain some of the tracings.

\section{RESULTS}

The ability to recognize P2 is set out in Table II, which shows that it was seen constantly and well in 10 of the 18 patients.

The timing of P2 in the first ten cases is summarized in Table III. The A2-P2 interval was most often 0.07 or $0.08 \mathrm{sec}$, but varied from 0.06 to $0.12 \mathrm{sec}$.

Fig. 1-3 illustrate some of the phonocardiograms. 
TABLE I

Clinical Details of the Eighteen Cases

\begin{tabular}{|c|c|c|c|}
\hline $\begin{array}{l}\text { Case } \\
\text { No. }\end{array}$ & $\begin{array}{c}\text { Age } \\
\text { (years) }\end{array}$ & $\begin{array}{l}\text { A2-P2 interval } \\
(\mathrm{sec} .)\end{array}$ & Indication for operation \\
\hline $\begin{array}{l}1 \\
2 \\
3^{*} \\
4 \\
5\end{array}$ & $\begin{array}{l}2 \\
2 \\
2 \\
3 \\
3\end{array}$ & $\begin{array}{l}0.06 \\
0.08 \\
0.06 \text { (inconstantly) } \\
0.08 \\
0.09\end{array}$ & $\begin{array}{l}\text { Repeated attacks of deep cyanosis } \\
\text { Angina } \\
\overline{\text { Cerebral thrombosis }} \\
\text { Dyspnoea on exertion, falling be- } \\
\text { hind twin in development }\end{array}$ \\
\hline $\begin{array}{c}6 \dagger \\
7 \\
8 \\
9 \\
10 \S\end{array}$ & $\begin{array}{l}3 \ddagger \\
3 \\
4 \\
4 \ddagger \\
4\end{array}$ & $\begin{array}{l}\overline{0.06} \\
0.07 \text { (inconstantly) } \\
-\end{array}$ & $\begin{array}{l}\text { Angina } \\
\text { Cyanotic attacks } \\
\text { Periods of increasing cyanosis } \\
\text { Increasing cyanosis } \\
\text { Increasing frequency of attacks of }\end{array}$ \\
\hline $\begin{array}{l}11 \\
12 \\
13^{*} \\
14 \\
15 \\
16^{* *} \\
17 \\
18\end{array}$ & $\begin{array}{c}4 \\
4 \\
8 \\
8 \ddagger \\
8 \\
9 \ddagger \\
9 \\
12\end{array}$ & $\begin{array}{l}0.07 \\
0.07 \\
0 \cdot 10-0 \cdot 12 \\
- \\
0.07 \\
0.07 \\
0.08 \text { (inconstantly) } \\
0.08\end{array}$ & $\begin{array}{l}\text { Continually squatting } \\
\text { Frequent squatting; easily tired } \\
\text { Decreasing exercise tolerance } \\
\text { Decreasing exercise tolerance } \\
\text { Decreasing exercise tolerance } \\
\text { Decreasing exercise tolerance } \\
\text { Decreasing exercise tolerance } \\
\text { Increasing cyanosis }\end{array}$ \\
\hline
\end{tabular}

* Operation not yet performed.

$\dagger$ Died just before operation.

¥ Routine phonocardiographic tracing unsatisfactory.

$\S \mathbf{P 2}$ could not be demonstrated after only one attempt. This patient was so uncooperative that a general anæsthetic was necessary for a simple clinical examination.

** P2 seen in low frequency trace only.

TABLE II

ReCognition of the Pulmonary Component of the SECOND SOUND

\begin{tabular}{|c|c|c|c|}
\hline \multicolumn{3}{|l|}{ Degree of recognition } & Number \\
\hline \multicolumn{2}{|c|}{ Well seen constantly in high frequency } & & 10 \\
\hline Seen inconstantly $\quad \ldots \quad \ldots$ & . & .. & 3 \\
\hline Technically unsatisfactory traces & . & . & 4 \\
\hline Not demonstrated $\quad \ldots \quad \ldots$ & . . & . & 1 \\
\hline
\end{tabular}

TABLE III

Number of CASEs Correlated WITH A2-P2 INTERVAL

\begin{tabular}{c|c}
\hline A2-P2 interval (sec.) & Number \\
\hline 0.06 & 2 \\
0.07 & 3 \\
0.08 & 3 \\
0.09 & 1 \\
$0.10-0.12$ & 1 \\
\hline
\end{tabular}

\section{Discussion}

Vogelpoel and Schrire (1960) analysed 63 cases, mainly adults, and their findings are summarized in Table IV. Their division into extreme, severe, moderate, and mild was based on broad clinical grounds and therefore it is difficult to know how they compare with the present series. Probably these 18 patients would be in either the severe or moderate group. Of the 10 patients in whom P2 could be readily demonstrated it was easily heard in four. Failure in four patients because of unsatisfactory traces and inconstant demonstration in three is attributed to the fact that these traces were done in a routine fashion with regard to the type of murmur, rather than with a view to demonstrating P2. Subsequently, P2 has been demonstrated in every case. 


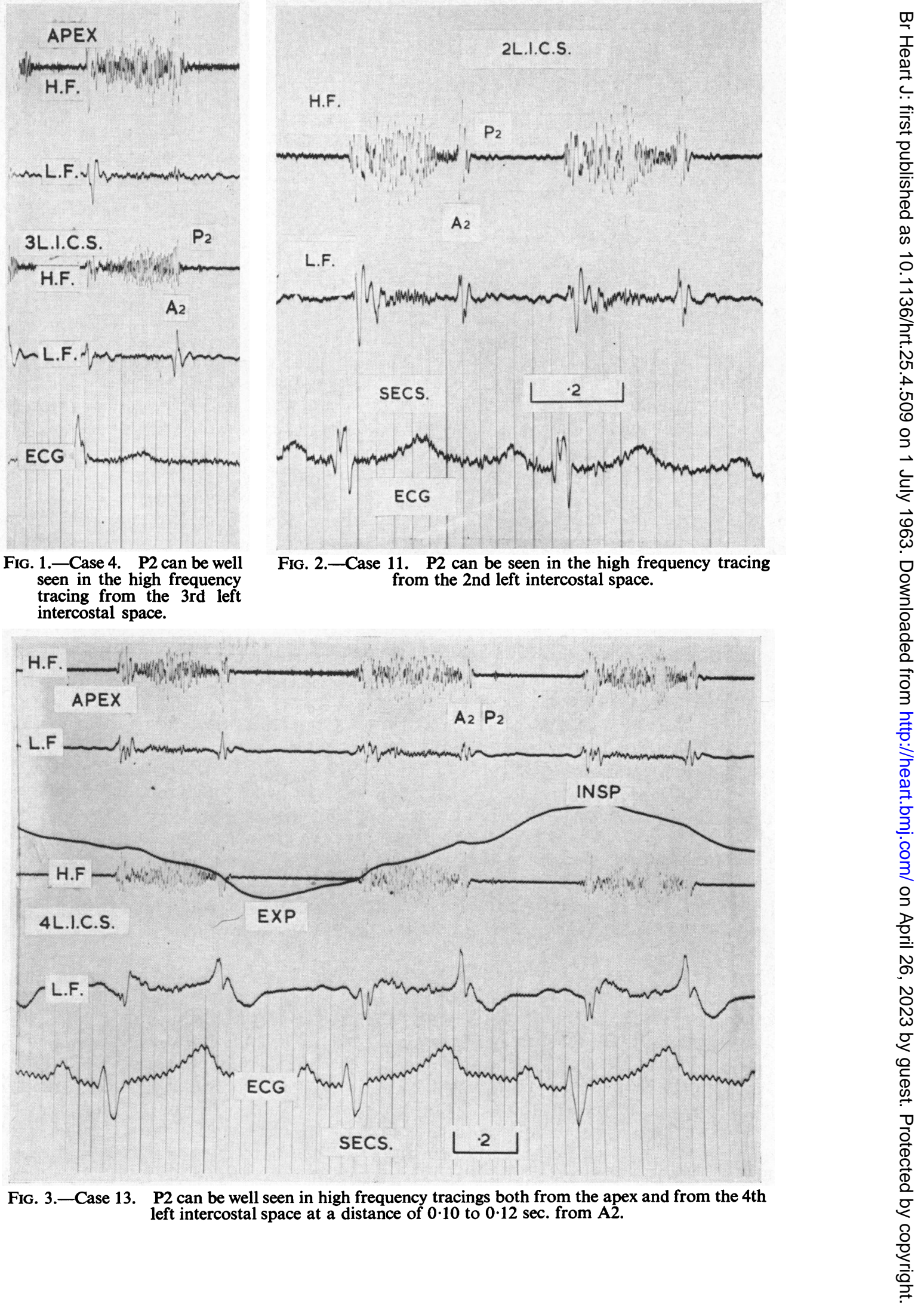


TABLE IV

Frequency of Demonstration of P2 in Fallot's Tetralogy of Varying Degrees of Severity, Adapted from VOGELPOEL AND SCHRIRE (1960)

\begin{tabular}{lccc|c|c}
\hline \multicolumn{2}{c|}{$\begin{array}{c}\text { Severity of the Fallot's } \\
\text { tetralogy }\end{array}$} & Total No. & $\begin{array}{c}\text { Number in which P2 } \\
\text { could be demonstrated } \\
\text { phonocardiographically }\end{array}$ \\
\hline Extreme &. & $\ldots$ &. & 6 & 0 \\
Severe &. & $\ldots$ &. & 18 & 0 \\
Moderate &. & $\ldots$ &. & 17 & 3 \\
Mild &. &.. &. & 21 & 18 \\
\hline
\end{tabular}

Grishman, Bleifer, and Donoso (1960) claim that "With the aid of phonocardiography alone, one may differentiate tetralogy of Fallot from severe pulmonary stenosis and patent foramen ovale with a right to left shunt". One of the features they stress is that the second sound is usually single (aortic) and often loud in Fallot, whereas in the other condition wide splitting has been demonstrated in 85 per cent of cases by Leatham and Weitzman (1957). In the light of the facts presented in this paper the presence or absence of $\mathrm{P} 2$, in the carefully recorded phonocardiogram is not a differential point.

Reported reference to P2 occurring $0.04 \mathrm{sec}$. after A2 in classical tetralogy of Fallot must have been caused either by wrongly identifying a low frequency vibration as $\mathrm{P} 2$, or by mistaken diagnosis (e.g. transposition with pulmonary stenosis). The closest A2-P2 interval in my series was $0.06 \mathrm{sec}$. and the largest varied between 0.10 and $0.12 \mathrm{sec}$.

Vogelpoel and Schrire (1960) state "Phonocardiographic proof that the sound was the pulmonary component was based on its localization to the pulmonary area, its occurrence before the summit of the " $v$ ' wave in the synchronously recorded phlebogram and its intensification after phenylephrine". In this series jugular phlebograms were not recorded lest the child's equilibrium be further disturbed, and phenylephrine was not given for similar reasons. Acceptance of localization of the pulmonary component to the pulmonary area as one of the criteria of its identification is possibly one of the reasons why $\mathrm{P} 2$ has not been heard or demonstrated by other observers.

In my series P2 could be heard extremely well in the fourth left intercostal space as well as the second left intercostal space in some. In others it could be heard only in the third and fourth left intercostal spaces and in one it was heard equally well at the apex as at the fourth left intercostal space (Case 13, Fig. 3). This is not surprising when one considers that the hypertrophied right ventricle extends towards the apical region. Just as A2 can sometimes be best heard at the apex when this is occupied by the left ventricle, so it can be argued P2 should be best heard at the apex when this is occupied by the right ventricle. That this is not the case in pulmonary valve stenosis could be related to the fact that the post-stenotic dilatation of the pulmonary artery acts as a sounding chamber for P2.

It is well known also that in infundibular stenosis the infundibular chamber may be quite long, with its base extending well towards the cardiac apex. It is possible that vibration of the fibrous tissue at the right ventricular end of the infundibulum may be the cause of the P2 that is audible in Fallot's tetralogy rather than pulmonary valve closure itself. Cardiac catheterization in Case 13 (Fig. 3) where P2 was well heard at the apex demonstrated a long infundibular chamber.

The only other causes of a sharp sound between $0 \cdot 08-0 \cdot 12 \mathrm{sec}$. after A2, namely mitral and tricuspid opening snaps, sharp third sounds of cardiomyopathy, and normal third heart sounds can be eliminated as follows: abnormal mitral and tricuspid valves are unusual in association with classical Fallot's tetralogy, and secondly, conditions of increased mitral and tricuspid blood flow do not exist. There is nothing in histological reports to indicate that the right ventricular muscle in Fallot's tetralogy resembles that of a cardiomyopathy. 
The nature of the extra sound, with its very sharp quality and the ability to record it in the high frequency, as seen in the tracings (Fig. 1,2,3), is against a third heart sound being responsible. In Case 13 the extra component was heard to increase in intensity on inspiration at the apex, and yet its distance from A2 decreased (Fig. 3).

It has not been possible to demonstrate any change in the A2-P2 interval after anastomotic operations, because the anastomotic murmur dominated the tracings, obscuring P2. Its demonstration in the fourth left intercostal space or towards the apex may be of value in the diagnosis of Fallot's tetralogy.

The significance of the demonstration of P2 is probably an academic one. It does not help to distinguish pulmonary stenosis with a ventricular septal defect from simple pulmonary stenosis. Failure to demonstrate it, after careful phonocardiography, in a cyanosed child with features of Fallot's tetralogy gives additional clinical evidence of pulmonary atresia.

\section{SUMMARY}

Using phonocardiography it has been found that P2 can be demonstrated in nearly all cases of classical tetralogy of Fallot in infants and children. The frequency with which it can be demonstrated depends to a great extent on the amount of time one is prepared to spend with the child.

I wish to thank Dr. C. Fortune, Dr. I. Wallman, and other physicians at Princess Margaret Hospital, Perth, who referred cases to me, and the technical staff of the Cardiac Clinic Princess Margaret Hospital for their co-operation.

\section{REFERENCES}

Grishman, A., Bleifer, S. B., and Donoso, E. (1960). Advanc. intern. Med., 10, 179.

Leatham, A., and Weitzman, D. (1957). Brit. Heart J., 19, 303.

Vogelpoel, L., and Schrire, V. (1960). Circulation, 22, 73. 